\title{
Ideofones do changana e o princípio da marcação
}

\author{
Ezra Alberto Chambal Nhampoca \\ Universidade Federal de Santa Catarina e \\ Universidade Eduardo Mondlane
}

\section{Introdução}

O Changana é uma língua do grupo Bantu, falada em quatro países na África Austral, incluindo Moçambique. O presente trabalho debruça-se sobre ideofones do Changana e constitui uma subseção da tese de doutorado. Os ideofones foram definidos pela primeira vez por Doke (1935) como sendo a associação entre um determinado som, cor, estado, dor, intensidade, etc. e a consequente reação na mente do indivíduo. O objetivo principal do capítulo é de descrever os ideofones da língua Changana tendo em conta o Princípio da Marcação, mais particularmente, três características apresentadas por Givón (2001, p.1): Princípio meta-icônico da marcação que postula que as categorias estruturalmente mais marcadas, tendem, igualmente, a serem funcionalmente mais complexas; 2) Frequência: a categoria não marcada é mais frequente em relação à marcada; 3) Dependência do contexto, que tem a ver, segundo Givón $(1995,2001)$ com o fato de que a marcação não diz respeito apenas a categorias linguísticas, mas também a categorias comunicativas em que elas ocorrem, com o objetivo de analisar como é que os ideofones do Changana se comportam, no que diz respeito a este princípio. A nossa hipótese é a de que, na língua Changana, os ideofones desempenham prototipicamente, a função predicadora, tal como os verbos, mas os verbos são predicadores básicos, portanto, não marcados, predicam o estado básico das coisas e os ideofones são predicadores marcados que predicam em situações específicas, em que os falantes pretendam elucidar certos aspectos de suas ações, de um modo que o significado do verbo não cobriria.

Como referencial teórico, tivemos como base os autores Bybee (2010), Givón (1995), entre outros. Os dados usados foram extraídos de dois instrumentos lexicográficos: primeiro, uma base de dados constituída durante a pesquisa de Nhampoca (2010) e, o segundo, é o Dicionário Changana-Português de Sitoe (1996). Desses instrumentos, selecionamos 05 ideofones que possuem um 
verbo correspondente na língua em análise. A análise mostrou que o Princípio de Marcação é relevante para o estudo de ideofones do Changana e auxilia-nos na distinção dos ideofones dos verbos, uma vez que verificamos que os ideofones são predicadores marcados e os verbos não marcados. O trabalho apresenta uma breve abordagem sobre questões sociolinguísticas de Moçambique, uma revisão bibliográfica, junto com uma breve fundamentação teórica, procedimentos metodológicos, na sequência, a análise de dados, as considerações finais e, por fim, a bibliografia.

\section{Questões sociolinguísticas de Moçambique}

A República de Moçambique situa-se na África Austral. Está dividida administrativamente em 11 províncias e 128 distritos. O último censo populacional oficial foi realizado em 2007 e apurou que Moçambique possuía 20.632.434 habitantes (6.269.621 na zona urbana e 14.362.813 na zona rural) (INE, 2010, apud Ngunga; Faquir, 2011). Projeções posteriores à data do último censo apontam para cerca de 22.000.000 habitantes em 2014 (Timbane, 2014) e 26.423.623 habitantes em 2016 (INE, 2016).

É um país multilíngue e multicultural, como sucede com a maioria dos países africanos. As características acima descritas conferem ao país uma diversidade cultural e linguística, sendo a diversidade linguística de Moçambique uma das suas principais características socioculturais. A maior parte da população pertence aos povos Bantu. É importante referir aqui que, majoritariamente, sua população habita nas zonas rurais e preserva a sua cultura, hábitos, costumes e as suas línguas locais, sempre respeitando a tradição oral (Timbane, 2014). A constituição da República de Moçambique indica que o Português é a única língua oficial. (MOÇAMBIQUE, 2004, Art. 10). A capital é Maputo, sua maior cidade, situada na zona sul do país.

\subsection{As línguas Bantu moçambicanas (LBm)}

No que respeita ao número de línguas Bantu faladas em Moçambique, não há consenso. Algumas fontes, como por exemplo, a Ethnologue ${ }^{1}$ e Kroger (2005, apud UEM - SLB, 2014) consideram que há cerca de 40 línguas, como se pode verificar no mapa linguístico abaixo. 
Mapa 1: Mapa de Línguas Bantu de Moçambique

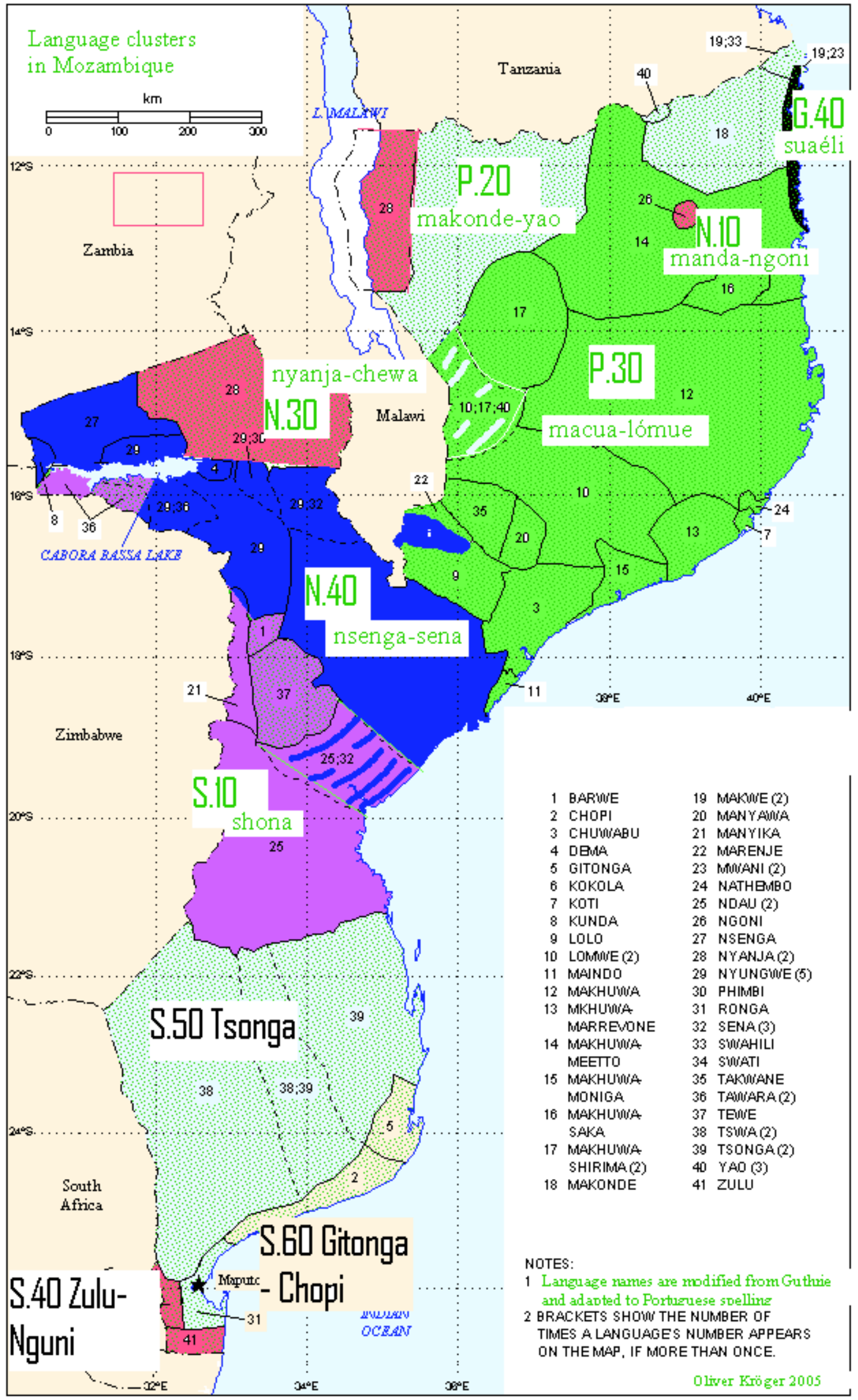

Fonte: Folheto de apresentação da UEM - Secção de Línguas Bantu (UEM, 2014) 
Sobre este assunto, Sitoe (2014, p. 40-41) afirma que, em Moçambique

na ausência de um atlas linguístico, o Relatório do "I Seminário sobre Padronização da Ortografia de Línguas Moçambicanas" (NELIMO, 1989), vem sendo tomado como a principal obra de referência sobre esta matéria [...] O mapa linguístico apresentado neste documento identifica 20 línguas moçambicanas. Contudo, este mesmo documento refere claramente que as línguas tratadas não constituem a totalidade das línguas faladas em Moçambique. O mapa não menciona o Cibalke e trata como uma mesma língua três variedades do grupo Shona, nomeadamente Cimanyika, Cindau e Ciutee. Adicionado a isto, para além das 17 línguas tratadas no II Seminário (Sitoe \& Ngunga, 2000), o mapa apresentado no relatório deste seminário indica ainda as línguas Kiswahili, Ekoti, isiSwazi e isZulu. Se se adicionar o Cibalke e as línguas do grupo Shona, teremos um total de 23 línguas moçambicanas mencionadas nos dois relatórios.

Já o folheto de apresentação da Seção de Línguas Bantu da Universidade Eduardo Mondlane (UEM - SLB) apresenta 20 línguas Bantu, faladas por $80 \%$ da população, quer como língua materna quer como língua segunda (SLB - UEM, 2014). Destas, 19 línguas são atualmente ensinadas pela SLB - UEM, são elas: Cibalke, Cicopi, Cindau, Cimanyika, Cinyanja, Cinyungwe, Cisena, Citshwa, Ciutee, Ciyaawo, Echuwabo, Ekoti, Elomwe, Emakhuwa Gitonga, Kimwani, Shimakonde, XiChangana ${ }^{2}$ e Xirhonga. A maior parte destas 19 línguas está presente no âmbito do ensino bilíngue, introduzido em 2002/2003 no país. Talvez seja por essa falta de consenso que Ngunga apud Laboratório de Línguas Africanas, UFMG (2015), defende que, dependendo dos vários pontos de vista, o número das línguas Bantu moçambicanas pode variar de 9 a 43 .

Para efeitos deste capítulo, optamos pela perspectiva da SLB da Universidade Eduardo Mondlane, por termos verificado, por um lado, que os que apontam para a existência de cerca de 40 línguas, na maioria dos casos, consideram variedades de uma mesma língua como língua, o que contribui para o aumento desse número e, por outro lado, as 23 línguas apresentadas por Sitoe (2014) incluem Kiswahili, isiSwazi e isZulu, línguas que, apesar de reconhecermos sua existência e circulação no território moçambicano, preferimos excluí-las da lista das línguas bantu faladas em Moçambique, por estas advirem de influência de países vizinhos como África do Sul para o caso do isZulu, Tanzânia para o Kiswahili e Suazilândia para o isiSwazi. Para além do Português e das línguas Bantu, outras línguas são faladas no território, como por exemplo, as de origem europeia: Francês, Espanhol, Inglês, Alemão; as de origem asiática e/ou línguas do Médio Oriente: Mandarim, Urdu, Gujurati, Hindi e Memane, (Nhampoca, 2015; Sitoe, 2014; Patel, 2006).

2. O termo XiChangana é usado como sinônimo do termo Changana. Nele, o prefixo xi- é referente à classe a que pertencem as línguas. 


\subsection{A língua Changana em Moçambique e na África}

O Changana (S.53, na classificação de Guthrie, 1967/71) é uma língua do grupo Bantu. De acordo com Sitoe (1996), esta língua pertence ao grupo Tswa-Ronga (com código S.50, na mesma classificação de Guthrie, 1967-71). Doke (apud Sitoe, 1996) designa este grupo pelo termo Tsonga. Fazem ainda parte deste grupo as línguas Tshwa (S.51) e Ronga (S.54). Os falantes das línguas Ronga e Tshwa conseguem comunicar-se com os falantes do Changana o que significa que são línguas inteligíveis. O Changana, para além de Moçambique, é falado na África do Sul, Swazilândia e Zimbabwe (Sitoe e Ngunga, 2000; Sitoe, 1996; Nhampoca, 2009). Portanto, consideramos que, pelo fato de ser falado nos quatro países, o Changana se revela como um importante veículo de comunicação formal e/ou informal para e entre comunidades dos quatro países onde é falado.

Em Moçambique, o Changana é falado nas províncias de Maputo, Gaza, Inhambane e na zona meridional das províncias de Manica e Sofala (Sitoe e Ngunga, 2000). De acordo com Ngunga e Faquir (2011), com base no Censo Populacional de 2007, o Changana é falado por cerca de 1.660.319 habitantes em Moçambique. É a $2^{\mathrm{a}}$ língua Bantu mais falada no país, com cerca de $10.5 \%$ de falantes, depois do Emakhuwa com cerca de $26.1 \%$ de falantes, segundo Ngunga e Faquir, (2011). De acordo com Sitoe (1996), o Changana apresenta as seguintes variantes: 1) xihlanganu, falada a sudoeste de Moçambique, nos Montes Libombos, abrangendo parte dos distritos de Namaacha, Moamba e Magude; 2) xidzonga ou xitsonga que é falada nos distritos de Magude, Bilene e parte de Massingir; 3) xin'walungu, variante falada no distrito de Massingir; 4) xibila, falada no distrito de Limpopo e parte do distrito de Chibuto; 5) xihlengwe que é falada nos distritos de Xai-Xai, Manjacaze, Chibuto, Guijá, Chicualacuala, Panda, Morrumbene, Massinga, Vilanculo e Govuro. Sitoe (1996) afirma que devido a grandes e frequentes movimentações das populações, torna-se cada vez mais difícil a localização precisa destas variantes. Para este trabalho tomamos como referência a variante Xidzonga, uma vez que os dados analisados foram recolhidos num local onde esta variante prevalece.

\section{Breve revisão: Ideofones em algumas línguas do mundo e no Changa- na, tentativas de definição}

Os ideofones são comumente definidos como uma representação viva de uma ideia num som. Uma palavra, muitas vezes onomatopeica, que descreve um predicado, é qualificativa ou funciona como advérbio em relação à forma, cor, som, cheiro, ação, estado ou intensidade (Doke, 1935). Esta é uma das definições mais citadas até agora. Outra definição semelhante, porque inspirada na de Doke 
(1935), é a de Ngunga (2004, p.195) que considera ideofone como "a associação entre um determinado som, cor, estado, dor, intensidade, etc., à consequente reação ou construção psíquica dos mesmos na mente do indivíduo/falante". Esta última definição faz-nos pensar que, "semanticamente, os ideofones estão ligados a campos específicos e diversos, tais como ações, sons, cores cheiros, posturas, atitudes, gestos, etc." (Sitoe, 1996, p.345).

Sitoe (1996) defende ainda que os ideofones se caracterizam pelo seu alto grau de especificidade. Já Beck (2005) defende que ideofones são expressões sinestésicas que se distinguem, como classe, através das suas propriedades sintáticas, morfológicas e fonológicas; da tendência de ter uma função emotiva e de estarem associados à fala e a registros dramáticos da fala. $\mathrm{O}$ ideofone é uma representação viva de uma ideia, num som (Kimenyi: s.p., s.d). Para melhor situar o leitor, apresentamos o exemplo do ideofone-dèke, comparado com o verbo -dekètà: -dèke $i d$. 1. de acionar, premir (p.e., um botão, um interruptor). 2. de dar uma palmada na mão da pessoa com que se conversa como forma de acompanhar a conversa (geralmente em fofoca); 3. De fazer fofoca.

1a). "Maria atemu dèke munghanu."

Maria MS1. VDef. MO1 ID= de dar uma palmada (leve) na mão de alguém 1. Amigo.

"A Maria deu uma palmada na mão da amiga."/ "A Maria fez -dekè na amiga"

1b) "Maria adèkètè munghanu."

Maria MS1. 15. dar uma palmada (leve) na mão de alguém 1. Amigo

'A Maria deu uma palmada na mão da amiga.'

No exemplo acima, o ideofone é polissêmico. Aqui como se trata de uma breve demonstração do funcionamento dos ideofones, iremos explorar apenas um dos significados, o significado 2 (de dar uma palmada na mão da pessoa com que se conversa como forma de acompanhar a conversa (geralmente em fofoca), para complementar a fofoca ou a concordância na fofoca.

No exemplo em (1a), pode-se observar que, como a sentença ocorre com um ideofone, -dekè, não é necessária a ocorrência de um verbo que exprima a ação. O ideofone, por si só, desempenha a função predicadora. Temos um agente (Maria), a entidade que dá uma palmada leve na mão de um destinatário, (a amiga da Maria), na sequência, temos o verbo defectivo (-te), que é, ao mesmo tempo, marca de passado e que se torna (ate) ao agregar o morfema a-. O morfema afunciona como marca do sujeito Maria (de $3^{\mathrm{a}}$ pessoa). Portanto ate indica para além da marca do sujeito, o tempo passado. O verbo defectivo, assim designado na terminologia bantu, é uma espécie de verbo dicendi que tem a mera função de 
situar no tempo e aspectualmente a ação/estado descrito pelo ideofone, agregando todos os morfemas que seriam aglutinados ao verbo se a predicação se desse por meio de um, ou seja, o verbo defectivo agrega todos os morfemas de indicam tempo, aspecto, número, pessoa.

Na língua, quando a predicação se realiza por meio de um verbo, esses morfemas se aglutinam ao verbo (esta é mais uma diferença entre verbos e ideofones). Uma vez que o ideofone não aglutina esses morfemas, eles se agregam ao verbo defectivo, como em "Maria atemu dèke munghanu", em que o morfema mu-, que indica a classe nominal, pessoa, número, bem como a de tempo (-te), está agregado ao verbo defectivo - te e não ao ideofone, contrariamente ao que ocorre em (1b), onde o morfema a- que é marca de sujeito e de número aglutina-se ao verbo -dekètà, bem como a marca do passado (-te). O verbo defectivo, na sua estrutura semântica só tem o traço tempo. Não se consegue descrever NADA com estes verbos (defectivos) isolados. Eles apenas introduzem os ideofones e/ ou os discursos direto e indireto. Para mais detalhes (cf. Nhampoca, 2010; 2016). No exemplo (1a), não ocorre nenhum verbo, a não ser o defectivo, e o ideofone -dekè desempenha a função predicadora e em (1b) a predicação é feita pelo verbo-dekètà.

Embora haja pequenas diferenças de abordagens, na definição do ideofone, pensamos que todas as posições aqui apresentadas se assemelham e defendem que um ideofone é "o fenômeno através do qual alguns sons da linguagem humana podem, do ponto de vista semântico, combinar a figura mental com os sons da fala (Sitoe, 1996; Langa, 2004). Estas definições são gerais e não distinguem claramente os ideofones de palavras de outras categorias na língua, uma vez que se aplicam a qualquer signo, por isso, nossa intenção neste momento, no âmbito da nossa tese de doutorado, é buscar uma definição mais precisa, com base em teorias da Linguística Cognitiva.

Enquanto, por um lado, alguns autores restringem a ocorrência de ideofones a certas línguas do mundo, por exemplo, Doke (1935) restringe sua ocorrência às línguas Bantu apenas; Kulemeka (1995) realça a existência de ideofones em dois grupos de línguas do mundo: as africanas e as asiáticas; Epps e Salanova (2012) destacam a ocorrência de ideofones nas línguas indígenas da Amazónia. Por outro lado, alguns afirmam a ocorrência dos ideofones em todas as línguas do mundo. Ferreira (2011, p.403), por exemplo, defende que: "ideofones são atestados em todas as línguas do mundo, porém, as línguas diferem na extensão em que os empregam". Contudo, a autora não mostra nem faz referência à respectiva extensão do emprego dos ideofones nas diferentes línguas do mundo. A ocorrência de ideofones como categoria universal, ou seja, em todas as línguas é também 
defendida por Voltz e Killiam-Hatz's (2001 apud Gabas Jr.; Auwera, 2004), na sua proposta de classificação, ao afirmar que os ideofones são uma categoria gramatical e universal. Para Biriate (2014, p. 01) "embora nem em todos os idiomas se manifestem na mesma medida, os ideofones são uma característica universal ou quase universal da linguagem humana".

Com tudo o que se discutiu acima acerca dos ideofones, podemos afirmar que a sua conceituação é diversificada (Ferreira, 2011). Essa diversificação faz com que, não poucas vezes, como indica Ferreira (2011), considere-se que a noção de ideofonia é enganosa, referindo-se a interpretações simplistas que se têm feito sobre o conceito. Araújo (2009) defende que o fato de não se oferecer uma definição clara ao termo ideofone faz com que sejam agrupados elementos de natureza diversa nessa categoria. Um dos exemplos é o fato de, por muito tempo, os ideofones terem sido tratados como onomatopeias, quando estudos posteriores provaram que ideofones eram muito mais do que onomatopeias (Doke, 1968 apud Ngunga, 2004). E mais se provou que em algumas línguas, como o Changana, língua objeto deste trabalho, as onomatopeias são uma subclasse de ideofones, constituindo os chamados ideofones onomatopáicos (Nhampoca, 2010). O próprio Doke notou a diferença entre onomatopeias e ideofones e, segundo Araújo (2009), apesar de Doke não apresentar uma definição formal para ideofones, ele deu uma guinada no assunto ao estabelecer uma distinção entre ideofones, onomatopeias e sons imitativos e ao propor uma classe de palavras especial para agrupar ideofones.

De acordo com Araújo (2009), perante estas variações da definição do termo ideofone na literatura e, apesar disso, não haver uma que consiga abranger sua heterogeneidade, as tentativas mais bem sucedidas são as que conseguem enquadrar as múltiplas características dos ideofones em grupos prototípicos. Duas tentativas de definição que pensamos que se aproximam da hipótese que propomos neste trabalho são as de Epps e Salanova (2012) e Ferreira (2011). Epps e Salanova (2012, p.21) defendem que ideofone é "o sucedâneo linguístico mais próximo de um ato físico, não verbal", ou seja, "os ideofones conferem uma concretude sensorial e emotiva à narrativa" (Epps; Salanova, 2012, p. 21). E Ferreira (2011) afirma que quando se descreve uma ação, evento, estado, com recurso aos ideofones, eles invocam toda a imagem, toda a atitude narrada pelo falante. Estas são as perspectivas que adotamos apenas como ponto de partida para uma definição de ideofone e, com esta pesquisa, pretendemos apresentar uma definição mais completa e clara.

Conforme já salientado, os ideofones ocorrem também em várias línguas do mundo, por exemplo, nas línguas asiáticas. Estudos linguísticos asiáticos têm 
dado muita atenção à associação natural existente entre som e significado (Kulemeka, 1995). Por isso, há muito interesse nestas línguas pelo estudo dos ideofones. Kulemeka atesta que, em línguas asiáticas, os ideofones ocorrem mais como sons simbólicos do que como categoria de palavras. $\mathrm{O}$ autor afirma que nessas línguas verifica-se uma relação estreita entre a forma como a palavra soa e o som feito pelo objeto no mundo real, daí considerar por icônico o tipo de relação que se dá nestas línguas.

Ao debruçarem-se sobre aspectos gramaticais das línguas indígenas brasileiras, em particular dos povos da Amazônia, Beier et al., (2000 apud Epps \& Salanova, 2012) enumeram várias práticas discursivas amplamente difundidas entre os povos amazônicos que incluem o uso maciço do diálogo, desde a encenação de diálogos altamente ritualizados até o "eco" dos ouvintes que acompanham as narrativas: o choro ritual e certas formas especiais ou rituais da língua.

Os autores defendem que a maior parte de tais práticas acaba obtendo uma dimensão cultural e influenciando elementos gramaticais, lexicais e discursivos das línguas em que elas ocorrem. Os ideofones são um exemplo disso. Epps \& Salanova (2012, p. 21) referem que os ideofones são "um recurso linguístico que se encontra com frequência nas narrativas em línguas amazônicas". Segundo os mesmos autores, em muitos casos, os ideofones nas línguas indígenas amazônicas constituem uma categoria lexical que se distingue claramente das outras, como por exemplo, apresentam suas próprias "estruturas silábicas ou segmentos fonéticos que não se encontram em outros lexemas, e com propriedades morfológicas diferentes. Os ideofones com frequência representam sons, mas podem também representar movimentos ou sensações" (Epps \& Salanova, 2012, p. 21).

Outra língua indígena em que ocorrem ideofones é o Parkatêjê, uma língua falada por uma comunidade com o mesmo nome. A comunidade Parkatêjê localiza-se no sudeste do estado do Pará, próximo do município de Bom Jesus do Tocantins (Ferreira, 2011). Ferreira observa que, em contos orais do Parkatêjê, quando se descreve uma ação, evento, estado, o ideofone invoca toda a imagem, toda a atitude narrada pelo falante ${ }^{3}$. Várias ocorrências de ideofones, na língua, foram também observadas na conversação diária na comunidade, durante as atividades cotidianas dos Parkatêjê. A autora afirma que há várias outras palavras que, não sendo ideofones, são empregadas como ideofones, isto confirma a posição defendida por Araújo (2009), segundo a qual, a recorrente imprecisão no estudo e na

3. Notamos que o que é descrito por Ferreira (2011) ocorre com os ideofones do Changana, pois ações descritas com uso de ideofones invocam cenas completas e vivas de uma forma mais intensa em relação às descritas por verbos (Nhampoca, 2010). 
definição dos ideofones faz com que muitas vezes sejam incluídos elementos de outra natureza na categoria ideofone.

Gabas Jr. e Auwera (2004) descrevem os ideofones da língua indígena Karo. Esta língua, conforme os autores, é falada também na região amazônica. É a única língua da família Ramarama do grupo Tupi. Embora a língua Karo viva em contato intenso com o Português desde os anos 1950, a língua continua sendo falada na comunidade e sendo aprendida pelas crianças. Para a comunidade, o Português é usado apenas como língua de contato (Gabas Jr.; Auwera, 2004, p. 397). Os autores afirmam que existem ideofones na língua Karo, os quais exibem um comportamento gramatical diferente de outros elementos da gramática da língua. Como atestam Gabas Jr. e Auwera (2004, p. 401), os ideofones nesta língua são semanticamente semelhantes aos verbos por seus significados transmitirem descrições de ações/estados, mas os ideofones não estão sujeitos aos mesmos processos de flexão e derivação. Nestes aspectos, os ideofones do Karo são semelhantes aos ideofones do Changana, pois como veremos mais abaixo, ideofones são diferentes dos outros elementos da gramática do Changana e, também, assemelham-se aos verbos, por transmitir descrições ações /estados, apesar das diferenças de flexão e derivação existentes entre os verbos e ideofones do Changana.

Araújo (2009) apresenta um estudo sobre os ideofones na língua Sãotomense, um crioulo de base portuguesa falado nas ilhas de São Tomé e Príncipe. Este autor recorre a dados trabalhados por Ferraz (1978 e 1979) e relata também dificuldades existentes para descrever ideofones nesta língua. Araújo $(2009$, p. 25) afirma que Ferraz "descreve os ideofones no Sãotomense sem, contudo, oferecer uma definição clara para o termo". Por exemplo, Ferraz define ideofone como o elemento de uma categoria que agrupa qualquer palavra cuja forma seja repetida ou reduplicada, ou modificadora de um verbo ou nome. Araújo afirma não concordar com esta definição, pois, em Sãotomense, são formas obrigatoriamente presas a seus elementos da colocação, sendo que colocação é "entendida como uma combinação frequente ou preferencial de palavras cujas unidades resultem em uma expressão semi-idiomática" (Araújo, 2009, p. 25).

A nosso ver, essa colocação a que Araújo se refere é a combinação do ideofone e o verbo dicendi ou defectivo que sempre antecede o ideofone (Gabas Jr.; Auwera, 2004; Sitoe, 2012). Araújo afirma também que os ideofones no Sãotomense possuem estruturas fonológicas próprias, com destaque à harmonia vocálica como uma das características marcantes dos ideofones na língua Sãotomense. Quanto às origens dos ideofones na língua São tomense, Araújo (2009) atesta que ideofones ocorrem tanto nas línguas consideradas de substrato da África Atlântica como em 
outros crioulos da região. Este autor acrescenta que tal fator pode significar que os ideofones decorram de um substrato comum, de origens comuns ou ainda de influências mútuas entre as línguas.

Apesar dessa tentativa de aproximação do Sãotomense a outras línguas da região, no que respeita à ocorrência de ideofones, Araújo (2009) menciona que das várias línguas estudadas naquela região, as únicas que apresentam uma correspondência são os crioulos de base portuguesa do Golfo da Guiné (angolar, principense e fá d'ambu), o que se deve, grande modo, à origem comum destes crioulos e também por serem línguas que se interinfluenciam multiplamente. $\mathrm{O}$ autor refere-se também ao fato de que tentativas de encontrar correspondentes em línguas Bantu e as da África Atlântica foram infrutíferas. Seguindo com as características, Araújo (2009) refere-se ao processo morfológico da reduplicação e esclarece que no são tomense os ideofones podem passar por processos de reduplicação parcial ou total, processo verificado também em ideofones do Changana.

\section{Ideofones no Changana}

Autores como Miti (2006), Langa (2004), Ribeiro (2010), Ngunga (2004), Biriate (2014), Kulemeka (1995), entre outros que têm vindo a pesquisar sobre ideofones, destacam a existência de várias dificuldades para se trabalhar com eles. E apontam que essas dificuldades decorrem, entre várias razões, pelo fato de a categoria ideofones não existir nas línguas Indo-europeias (Miti, 2006; Langa, 2004). Biriate (2014) salienta que os ideofones são mais fáceis de identificar numa dada língua e difíceis de definir. Linguistas têm sido desafiados com a existência, em várias línguas do mundo, desta classe de palavras tida como específica e relacionada à descrição de eventos (Ferreira, 2011).

Os ideofones na língua Changana são considerados partes do discurso (Sitoe, 2012). Este autor inclui os ideofones na sua proposta de apresentação das oito principais partes do discurso da língua. Como já vimos, foi Doke quem primeiramente apresentou a proposta de separação dos ideofones como uma categoria. Ngunga (2004) afirma que em estudos anteriores a 1968, (Doke 1931, 1935), incluía-se esta categoria de palavras no grupo das onomatopeias geralmente definidas como palavras que imitam ou reproduzem ruídos produzidos por animais, pássaros, coisas, etc. Portanto, apesar de Doke (1935) ter introduzido o termo ideofone anteriormente, só a partir de 1968 é que se começa a considerar os ideofones como uma categoria gramatical distinta das outras. Ainda sobre esta categoria gramatical, Langa (2004, p. 59), defende que Doke "nomeou-os de ideofones por se ter apercebido que a terminologia que considera cinco categorias lexicais principais a saber: N(ome), V(erbo), ADJ(ectivo), ADV(érbio) e PREP(osição) 
não cobre a semântica que estas palavras transportam" pois, semanticamente, "os ideofones estão ligados a campos diversos, tais como ações, sons, cheiros, posturas, atitudes, gestos, etc." (Sitoe, 1996, p. 345).

Ribeiro (2010), sobre os ideofones do Changana, também alerta para o perigo de confundir estes com as onomatopeias. $\mathrm{O}$ autor afirma que os ideofones podem ser semelhantes às onomatopeias no impulso e na emoção, mas diferem das onomatopeias pelo papel que desempenham na linguagem. A onomatopeia limita-se a imitar sons, enquanto que o ideofone para além da imitação de sons, pode ainda expressar ações, modos, qualidades, estados, fenômenos da natureza, quietude, silêncio, etc. (Ribeiro, 2010). Ngunga (2004, p. 196) considera que "é importante observar que ideofones e onomatopeias são duas categorias de palavras que podem ser incluídas num único grupo através da inclusão destas no grupo daquelas, uma vez que ideofones são palavras-imagens, aquelas que, ouvidas, criam uma imagem [...] criam uma imagem na psique do ouvinte". Ngunga afirma isso em relação aos ideofones nas línguas Bantu em geral, porém, este fator se verifica particularmente, na língua Changana, com a ocorrência do que designamos por ideofones onomatopáicos (Nhampoca, 2010).

Sobre os ideofones do Changana, Ribeiro (2010, p. 129) acrescenta que "é difícil sintetizar e classificar o sentido destas palavras, tão largo é o seu campo". Ribeiro arrisca a afirmar que toda a noção verbal, na língua Changana, pode ser também expressa por um ideofone. Por esta razão, o autor considera que os ideofones constituem uma classe de palavras sem correspondente nas gramáticas europeias; estas palavras já foram, erradamente, classificadas de advérbios, descritivos, interjeições, onomatopeias, substantivos onomatopaicos, raízes primitivas, etc. (Torrend, s.d; Junod, s.d apud Ribeiro, 2010, p. 129). Nhampoca (2009, 2010 e 2016) apresenta alguns estudos em que discute vários aspectos de funcionamento dos ideofones do Changana. Resenhando tais estudos de Nhampoca e também apoiando-se em autores como (Sitoe, 2012; Ngunga, 2004; Langa, 2004; Kulemeka, 1995 entre outros), passamos a nos debruçar sobre os ideofones do Changana.

Nossa proposta: as definições até aqui apresentadas foram e continuam relevantes para o estudo dos ideofones. Contudo, pensamos que elas são muito gerais e não distinguem claramente os ideofones de palavras de outras categorias na língua, uma vez que o que elas apontam para características e/ou funções que podem ser de palavras de outras classes, como por exemplo, dizer que "ideofone é uma associação entre um determinado som, cor, estado, dor, intensidade, etc. e a consequente reação ou construção psíquica dos mesmos na mente do indivíduo/ falante" (Ngunga, 2004, p. 195) não distingue o ideofones de nomes e verbos, por 
exemplo, pois os falantes podem associar nomes e verbos, por exemplo, a determinado som, cor, estado, dor, intensidade, etc. Na verdade, o que irá estabelecer a diferença será a forma como o ideofone faz essa associação, pois o ideofone destaca não só os elementos centrais da ação, mas também os elementos periféricos de uma cena, uma ação que o verbo não destacaria.

\subsection{Sobre o Princípio da Marcação}

A marcação é um dos processos cognitivo-comunicativos presente nas línguas, que distingue unidades marcadas e não marcadas. Este princípio foi desenvolvido na escola de Praga a partir do refinamento da noção de valor linguístico proposta por Saussure e se baseava numa distinção binária de ausência/presença, ou seja, para os estudiosos da escola de Praga, com destaque a Jakobson e Trubetzkoy, a marcação se realiza pela presença de uma característica que está ausente no membro não marcado (Givón, 2001; Bybee, 2010; Silva, 2011). Como se pode verificar, esta visão já estava presente em estudos estruturalistas, no âmbito da variação, em que se considerava que um dos elementos é visto como uma escolha por defeito/omissão, o elemento não marcado.

Trubetzkoy (1939 apud Silva, 2011) destaca a marcação natural e a lógica. A marcação natural ocorre numa oposição entre segmentos, em que um difere do outro por possuir uma característica que o outro não possui. E a marcação lógica não se limita àquelas oposições, rege-se por razões internas ao sistema fonológico da língua. Silva (2011) atesta que Jakobson, em seus estudos sobre marcação, foi além da questão fonológica e fez uma abordagem semântica da marcação. Mais tarde, em 1941, Jakobson "descobre uma relação entre a marcação numa hierarquia universal de traços fonológicos" e estabelece que "os traços marcados implicam maior dificuldade de aprendizagem e uma maior facilidade de perda por parte de pessoas com afasia." (Silva, 2011, p. 32). Na teoria generativa standard, estudiosos como Chomsky e Halle (1968)

\footnotetext{
propõem uma teoria da marcação baseada num conjunto de convenções de marcação ou definições dos valores "marcado" / "não marcado" para os traços fonológicos em contextos particulares. A marcação concebe uma estrutura como preferida ou que surge por defeito/emissão. Os elementos marcados e não marcados são compreendidos como os que apresentam maior ou menor custo. Nesta abordagem, as regras da gramática universal é que atribuem um valor não marcado aos traços, por isso, os valores por omissão estão codificados na gramática universal e é nela que se baseiam as regras que fazem emergir os valores não marcados (Silva, 2011, p. 32-33, grifos do autor).
}

Com efeito, Silva (2011) considera que o que Chomsky e Halle (1968) propõem é uma visão universal e inata da marcação. Na Teoria da Otimidade, liderada por Prince e Smolensky (1993) a marcação é encarada como violação de 
um princípio da língua, uma vez que cada língua é definida por um conjunto de hierarquizações de princípios universais. Para eles "as restrições numa posição mais elevada, e que são raramente violadas, indicam os aspectos não marcados, enquanto as menos importantes, e que são violadas frequentemente, mostrem os aspectos mais marcados" (Silva, 2011, p.33). Bybee (2010) atesta que a teoria da marcação morfológica desenvolvida por Jakobson pode ser aplicada em alguns fenômenos sintáticos, como, por exemplo, o fato de ser universalmente aceito que uma oração não negativa será a não marcada e a negativa a marcada, pois enquanto a que está na forma negativa requer um marcador, a outra não. A voz ativa, por exemplo, parece ser não marcada, enquanto que a voz passiva é marcada, uma vez que a passiva apresenta uma estrutura mais complexa e uma frequência menor em relação à ativa.

A questão da complexidade também é discutida em Givón. O autor refere que a noção de marcação está associada à noção de complexidade, isto é, quanto mais complexa for uma estrutura, mais marcada será. Givón afirma que um determinado fenómeno linguístico é considerado marcado quando se mostra sensível aos seguintes critérios: (i) complexidade estrutural, (ii) baixa distribuição de frequência e (iii) complexidade cognitiva (Givón, 1995). De acordo com Givón (1995), em geral, estes princípios tendem a coincidir, embora devam ser encarados como independentes. No contexto do princípio da marcação, o elemento marcado tem tendência a ser mais complexo. Essa complexidade pode manifestar-se de variadas formas. No entanto, conforme Givón (2001), Silva (2011) e Cardoso (2014) para que uma estrutura seja considerada não marcada, há uma necessidade de se delimitar qual seria a estrutura marcada, dado que o conceito de "marcado" se realiza por oposição ao conceito de "não marcado" (Silva, 2011), ou seja, para que o princípio da marcação seja analisado é necessário que haja uma relação entre dois membros/elementos de um dado sistema.

Pensamos que isto se aplica ao fenômeno aqui analisado, ideofones, pois em comparação com os verbos, os ideofones são elementos marcados e os verbos elementos não marcados, sendo que os dois elementos na língua Changana desempenham uma função predicadora, conforme já colocado anteriormente. Conforme Cardoso (2014), uma estrutura marcada apresenta mais complexidade estrutural e cognitiva e é menos frequente; enquanto que uma estrutura não marcada apresenta menos complexidade estrutural e cognitiva e é mais frequente. Isso significa que a alta frequência de uma estrutura sinaliza uma baixa complexidade. Comparando ideofones e verbos podemos verificar que isso se confirma. Verbos, sendo predicadores não marcados, portanto, básicos, serão mais frequentes na língua, predicando no estado básico das coisas, enquanto que ideofones 
serão menos frequentes, predicando em situações marcadas, de forma marcada, por isso, apresentado uma complexidade estrutural e cognitiva, em relação aos verbos, como comprovam os exemplos apresentados na seção de análise.

Teorias da marcação morfológica e sintática, geralmente, fazem referência à iconicidade e à marcação semântica ou cognitiva. Neste âmbito, vários autores discutem a marcação cognitiva. Givón (2001) aponta características não menos importantes para o processo de marcação: Princípio meta-icônico da marcação - este considera que categorias estruturalmente mais marcadas, tendem, igualmente, a serem funcionalmente mais complexas; Frequência - a categoria não marcada é mais frequente em relação à marcada; Dependência do contexto aqui o autor defende que a marcação não diz respeito apenas a categorias linguísticas, mas também a categorias comunicativas em que elas ocorrem.

Clark e Clark (1978, apud Bybee, 2010) também discutem uma série de relações de marcação em termos de percepção e cognição humana. Eles afirmam, por exemplo, que cores básicas que correspondem ao espectro de cores facilmente captadas pelo córtex visual são nomeadas por palavras não marcadas como azul, vermelho, enquanto cores que se localizam em outras regiões do espectro, tais como azul céu, vermelho escuro são nomeadas por expressões mais complexas. Para os autores, o não marcado reflete o estado básico das coisas e o marcado uma mudança do estado das coisas e, ao causar uma mudança do estado básico das coisas, adiciona-se a essa mudança a complexidade e a linguagem reflete estes fatos cognitivos.

Para o fenômeno em estudo, os ideofones, o que se pode observar à luz desta teoria é que sendo os ideofones palavras que desempenham uma função predicadora, eles se comparam aos verbos, porém, verbos seriam os predicadores prototípicos, já que exercem essa função no estado básico das coisas, enquanto que ideofones seriam os predicadores marcados, tanto morfologicamente, por meio de uma estrutura mais complexa, quanto semântico-cognitivamente, uma vez que o falante, em geral, aciona o uso de ideofones em situações especiais, com objetivos de marcar, evidenciar ações, estados, situações de carga expressiva que os verbos não expressariam (Doke, 1935 e 1968 apud Ngunga, 2004; Beck, 2005; Sitoe, 1996 e 2012; Voltz e Killiam-Hatz's, 2001 apud Gabas Jr. e Auwera, 2004; Ferreira, 2011, Biriate, 2014). Sendo assim, nossa hipótese, em relação ao princípio da marcação, é a de que na língua Changana, verbos e ideofones desempenham a função predicadora, mas os verbos são predicadores básicos, não marcados e ideofones predicadores marcados, tanto morfologicamente assim como semântico-cognitivamente. 


\section{Procedimentos metodológicos}

Os dados que pretendemos analisar foram extraídos de dois instrumentos lexicográficos: a) parte de um corpus constituído durante a pesquisa e elaboração da nossa dissertação de Mestrado (Nhampoca, 2010). Para o Mestrado, o estudo com os ideofones foi somente no âmbito lexicográfico, contudo, acreditamos que, apesar de no presente pretendermos fazer uma análise utilizando o Princípio da marcação, os dados continuam válidos e aproveitáveis. Na altura, recorrendo à gravação em áudio e posterior transcrição e sistematização, recolhemos contos Changanas de tradição oral, no distrito de Chókwe, província de Gaza, no sul de Moçambique. Com a referida recolha, pretendíamos extrair ideofones, uma vez que notamos que os contos orais, na tradição Changana, são ricos em ideofones e escassos em textos escritos. Recolhemos também histórias de vida de falantes do Changana, pois verificamos que, na tradição Changana, as histórias de vida também são fontes ricas de ideofones.

b) uma recolha bibliográfica efetuada, para complementar os dados que já possuímos, no dicionário Changana-Português. Durante a pesquisa de mestrado, a partir desses dois instrumentos, constituímos um corpus maior, com o intuito de elaborar um pequeno dicionário de ideofones do Changana. Do dicionário de ideofones do Changana, selecionamos cinco (05) ideofones para permitir a captação das várias nuances dos mesmos. Os 05 ideofones são os que consideramos mais representativos em termos de aspectos de marcação. Para melhor comparação com os verbos, elegemos apenas ideofones que possuem, em termos de forma, um verbo correspondente na língua. Os ideofones selecionados são -cambùcambù, -foo, -khèhlè, -gìdìgìì e-pshandlà. E os verbos são-cambula, -foma, -khèhlèzàl-khèhlèkà, -gìdigikà e-pshandlaka/-pshandlasa

Como falantes nativos da língua Changana, usamos a introspecção para auxiliar nas conversas com os informantes, registro e sistematização e análise dos dados. E como pesquisadora, participei da elaboração dos dois instrumentos lexicográficos usados como fontes para a presente pesquisa. Este método será também usado na análise de dados.

Os ideofones selecionados serão analisados, comparando-os com os verbos correspondentes na língua, para mostrar que, apesar de verbos e ideofones serem predicadores na língua e, em termos de condições de verdade, apresentar significados sinônimos, os ideofones destacam cenas verbais marcadas, com realce para elementos de significado ausentes no verbo. Os ideofones, assim como os verbos no infinitivo, serão introduzidos por um hífen (-). Este sinal substitui o prefixo de classe nominal de ambos (ku-). Esta é uma estratégia que vem sendo usada nos estudos das línguas Bantu, para não sobrecarregar o texto com o prefixo ku- (Sitoe, 
1996 e 2012; Langa, 2015, Nhampoca, 2010).

A apresentação dos significados/definições dos ideofones será precedida pela abreviatura $i d$. que significa 'ideofone de' ou 'ideofone com significado de'. Quanto ao tom, salientamos que por causa da dificuldade em marcá-lo nos ideofones que ocorrem em sentenças, optamos por marcar o tom apenas nos ideofones soltos e não naqueles que ocorrem nas sentenças. Para isso, consideramos basicamente quatro critérios para a marcação do tom, a saber: 1) marcar os dois tons (alto e baixo); 2) marcar apenas os tons altos; 3) marcar apenas os tons baixos e 4) não marcar nenhum. Para o presente trabalho, recorremos ao critério 3, portanto, iremos marcar os tons baixos, seguindo a estratégia apresentada em Ngunga e Faquir (2011, p. 48) e Sitoe (1996), assumindo que onde não houver a marcação de tom, se trata de tom alto.

Para analisá-los, fornecemos o significado de cada ideofone e de cada verbo correspondente, por meio de uma definição e/ou explicação. Chamamos atenção ao fato de nas glosas, o material linguístico que se encontra entre parêntesis curvos diz respeito a ambos, o ideofone e o verbo, enquanto o que se encontra em parêntesis retos é referente apenas ao ideofone e é ele que muitas vezes nos dará insights para distinguir os ideofones dos verbos. Na sequência, fornecemos um exemplo, primeiro com o ideofone e depois com o verbo e a descrição de ambos. Feito isso, apresentamos uma breve explicação sobre o ideofone e o verbo. A análise termina com uma explicação geral referente a todos os dados analisados, vendo até que ponto o Princípio de marcação se aplica a eles, considerando as três características apresentadas por Givón (1995 e 2001).

\subsection{Análise de Dados}

Nesta parte do trabalho, analisamos os 5 ideofones selecionados, de acordo com os três princípios apresentados por Givón, Princípio meta-icônico da marcação, Frequência e Dependência do contexto. Começamos pelo ideofone cambùcambù:

Quadro 1: Os ideofones VS verbos

\begin{tabular}{|c|c|}
\hline Ideofone & Verbo \\
\hline $\begin{array}{c}\text {-cambùcambù } i d \text {. de caminhar ou correr nu/ } \\
\text { pelado, como veio ao mundo (o indivíduo do sexo } \\
\text { masculino). [COM MOVIMENTOS BRUSCOS E } \\
\text { INTENSOS] }\end{array}$ & $\begin{array}{c}\text {-cambula v.i. caminhar ou correr pelado, como } \\
\text { veio ao mundo (o indivíduo do sexo masculino). }\end{array}$ \\
\hline
\end{tabular}

\section{Ideofone}

2a) Zavala ali cambùcambù ndleleni!
1. Zavala VDef.
ID = de caminhar/correr nu
9.caminho/rua LOC. 
'O Zavala caminha (está caminhado) nu [com intensidade] na rua!

\section{Verbo}

2b) Zavala acambula ndleleni!

1. Zavala MS1 15. Caminhar/correr nu 9.caminho/rua LOC.

'O Zavala caminha (está caminhado) nu na rua!

$\mathrm{O}$ ideofone -cambùcambù descrito acima significa caminhar/correr nu, mas não cobre alguém do sexo feminino, aplicando-se apenas para o homem. $\mathrm{O}$ verbo -cambula também tem o significado de caminhar/correr nu, porém, o ideofone exprime isso de forma mais intensa e icônica e mais expressiva, daí que entendemos que a tradução não pode ser a mesma quando, por um lado se trata do ideofone e, de outro lado, quando se trata de um verbo, como se pode verificar nos exemplos $2 \mathrm{a}$ e $2 \mathrm{~b}$. Na sequência, o ideofone -foo:

Quadro 2: O ideofone -foo

\begin{tabular}{|c|c|}
\hline Ideofone & Verbo \\
\hline $\begin{array}{c}\text {-foo } i d \text {. de arder [DEMAIS] (como quando se põe } \\
\text { limão numa ferida aberta, ou os lábios devido ao } \\
\text { piripiri* muito picante). }\end{array}$ & $\begin{array}{c}\text {-foma } \text { vi. } \text {. arder (como quando se põe limão numa } \\
\text { ferida aberta, ou os lábios devido ao piripiri muito } \\
\text { picante). }\end{array}$ \\
\hline
\end{tabular}

*Diz-se pimenta no Português brasileiro.

\section{Ideofone}

3a) Minomo yamina yo foo hi sovori leli nijeke.

4. lábio PGen. Pron.Poss. VDef. ID= de arder de dor PREP. 4.piripiri PDEM. MS1 15.comer MP

'Os meus lábios estão ardendo demais por causa do piripiri que comi'.

\section{Verbo}

b) Minomo ya mina yafoma hi sovori leli nijeke.

4.lábio PGen. Pron.Poss. MS 15.arder de dor PREP. 4.piripiri DEM. MS1 15.comer MP

'Os meus lábios estão ardendo por causa do piripiri que comi'.

O ideofone -foo e o verbo -foma, em termos de significação central, são sinônimos, descrevem um evento em que uma entidade sente uma dor em seu corpo ou parte deste, mas o ideofone transmite mais do que o significado central transmitido pelo verbo, dando por exemplo, a ideia de a ação ter sido mais intensa. A seguir temos o exemplo do ideofone-gìdìgìdì: 
Quadro 3: O ideofone-gìdìgìdì:

\begin{tabular}{|c|c|}
\hline Ideofone & Verbo \\
\hline $\begin{array}{c}\text {-gìdìgìdì } i d \text {. de movimentar-se em massa [e IMPETUO- } \\
\text { SAMENTE] (diz-se de alguns animais e de pessoas). }\end{array}$ & $\begin{array}{c}\text {-gìdìkà } v . i \text {. movimentar-se em massa (diz-se } \\
\text { de alguns animais e de pessoas). }\end{array}$ \\
\hline
\end{tabular}

\section{Ideofone}

5a) Tihomu tili gìdìidì tiya combeni

MS10 boi MS10. Vdef. ID= de movimentar-se em massa MS10. 15. ir 5.rio LOC.

'Os bois movimentam-se em massa e impetuosamente para o rio'.

\section{Verbo}

b) Tihomu tigidika tiya combeni

MS10 boi MS10. 15. movimentar-se em massa MS10. 15. ir 5.rio LOC.

'Os bois movimentam-se em massa para o rio'.

Este ideofone é usado para descrever movimentos em massa de animais ou de pessoas. Sua contraparte na língua, é o verbo -gìdìkà, que também se difere do ideofone por este ser mais expressivo e mais marcado. Usado para mostrar ou dar a entender que a ação foi executada de modo não "normal". Depois do ideofone -gìdìgìdì, analisamos o ideofone -khèhlè:

\section{Quadro 3: O ideofone-khèhlè}

\begin{tabular}{|c|c|}
\hline Ideofone & Verbo \\
\hline -khèhlè $i d$. 1. de esboroar-se; 2 . de quebrar-se em \\
fanicos, desmoronar-se; 3. de quebrar [COMPLE- \\
$\begin{array}{c}\text { TAMENTE] (por exemplo a cabeça de alguém, com } \\
\text { um instrumento contudente. }\end{array}$ & $\begin{array}{c}\text {-khèhlèzà/khèhlèkà v.i.\&t. esboroar-se; 2. de } \\
\text { (por exemplo a cabeça de alguém, com um instru- } \\
\text { mento contudente. }\end{array}$ \\
\hline
\end{tabular}

\section{Ideofone}

4a) Mungoni ateyi khèhlè nhloko ya muyivi.

1.Mungoni MS1 VDef. MO ID.= de quebrar 9.cabeça PGen. 1.ladrão.

' O Mungoni quebrou completamente a cabeça do ladrão.'

\section{Verbo}

b) Mungoni akhehleze nhloko ya muyivi.

2.Mungoni MS1 15. quedrar 9.cabeça PGen. 1.ladrão.

' O Mungoni quebrou a cabeça do ladrão.'

O ideofone -khèhlè e o verbo -khèhlèzà se aplicam aos casos em que se quebra algo, usando um objeto contundente. Quando se emprega este ideofone, já 
se associa a ele o uso de um objeto pesado e contundente para golpear alguém ou algo, mais uma vez, o ideofone será acionado pelo falante para predicar mostrando intensidade, a força expressiva com que a ação ocorre e o verbo no estado normal, ou seja, não marcado. E por fim, analisamos o ideofone pshandlà:

Quadro 4: O ideofone pshandlà

\begin{tabular}{|c|c|}
\hline Ideofone & Verbo \\
\hline -pshandlà $i d$. 1. de cair e se esborrachar, rebentar- & -pshandaka/-pshandlasa vi.\&t. 1. de esborrachar- \\
-se [COMPLETAMENTE] (p. e., frutos maduros e & -se, rebentar-se (p. e., frutos maduros e coisas \\
coisas empapadas, geralmente em superfícies sóli- & empapadas, geralmente em superfícies sólidas); 2. \\
das); 2. de (fazer) rebentar [COMPLETAMENTE] & de (fazer) rebentar (por exemplo, frutos maduros \\
(por exemplo, frutos maduros e coisas empapadas, & e coisas empapadas, geralmente em superfícies \\
geralmente em superfícies sólidas). & sólidas). \\
\hline
\end{tabular}

\section{Ideofone}

6a) Payipayi rite pshandlà!

5. Papaia MS5 VDef. ID = de cair e se esborrachar completamente

'A papaia (madura) caiu e se esborrachou completamente!'

\section{Verbo}

b) Payipayi ripshandlakile!

5. papaia MS5 15. esborrachar-se MP.

'A papaia (madura) caiu e se esborrachou.'

O ideofone -pshandlà, diferentemente do verbo, para além de transmitir simplesmente a ideia de cair e esborrachar-se, rebentar-se, ele transmite também a ideia de intensidade na ação descrita, o que o torna marcado, pois vai além do significado central dado pelo verbo, agregando significados periféricos que o confere o estatuto de predicador específico que marca a ação descrita.

Note-se que, nas frases que ocorrem com ideofones, não é necessária a ocorrência dos verbos que exprimem ações tradicionalmente por eles descritas. Os ideofones, por si só, desempenham a função predicadora e tornam as frases sinônimas das que ocorrem com verbos, em termos de condições de verdade. O que também se nota é que, apesar de nos exemplos acima verificar-se que as frases que ocorrem com ideofones são sinônimas das que ocorrem com verbos (aceitando que sinônimos são itens lexicais cujos sentidos são idênticos no que diz respeito aos traços semânticos "centrais", ou seja, traços dados pelo predicador básico não marcado (verbo), mas que podem diferir apenas nos seus traços "periféricos", ou seja, traços dados pelo predicador não básico - marcado (ideofones)), para os falantes haverá uma diferença de interpretação, pois os ideofones (predicadores 
não prototípicos) acrescentam nuances "periféricas" ao sentido "central" dos verbos (predicadores prototípicos). As nuances periféricas aqui referidas resumem-se ao fato de o ideofone destacar um elemento de um frame, de um script, de uma cena verbal, indicando uma cena verbal marcada, com destaque para algum elemento da cena, que o verbo não destacaria.

O ideofone acrescenta, ao sentido básico dado pelo verbo, nuances que envolvem intensidade, expressividade, envolvimento emocional do(s) locutores, etc., agregados ao sentido "central" do significado proposicional (dado pelo verbo). Para que os verbos -cambula, -foma, -khèhlèzàl-khèhlèkà, -gìdigikà e -pshandlaka/pshandlasa tenham a mesma intensidade dos seus sinônimos ideofônicos -cambùcambù, -foo, -khèhlè, -gìdìgìì e-pshandlà, é necessário que se agreguem intensificadores adicionais e, mesmo assim, com os verbos dificilmente se chegaria ao significado evocado pelos ideofones -cambùcambù, -foo, -khèhlè, -gìdigìdì e -pshandlà, na língua Changana, pois os ideofones muitas vezes descrevem uma cena levada ao extremo na sua ocorrência. E, olhando para os três princípios estabelecidos por Givón $(1995,2001)$, podemos verificar que os três se aplicam para os ideofones do Changana. Ora vejamos:

Princípio meta-icônico da marcação: este diz que categorias estruturalmente mais marcadas tendem a ser funcionalmente mais complexas - pela análise feita aos exemplos, comparando ideofones com verbos, ideofones são mais complexos, tanto na sua estrutura morfológica, pois o ideofone ocorre sempre com um verbo defectivo que o situa temporal e aspectualmente, assim como, em termos de significado, o ideofone é também mais complexo, uma vez que exige, para a sua interpretação, a ativação de mais elementos em relação ao verbo, os elementos periféricos, por isso, concluímos que de fato a estrutura do seu significado é mais complexa e requer outros conhecimentos relacionados à sua iconicidade, ao seu aspecto dramatúrgico, resultando em uma complexidade cognitiva também.

No que se refere à Frequência, Givón $(1995,2001)$ estabelece que a categoria não marcada é mais frequente em relação à marcada, é o que ocorre na língua Changana em relação a ideofones e verbos, sendo os verbos predicadores prototípicos, que predicam ações no seu estado normal e ideofones predicadores marcados, que predicam ações num estado mais específico, agregando ao significado central elementos periféricos. Assim, podemos concluir que verbos são mais frequentes e ideofones menos frequentes.

E, por fim, quanto ao princípio da Dependência do contexto, que segundo o autor tem a ver com o fato de que a marcação não diz respeito apenas a categorias linguísticas, mas também a categorias comunicativas em que elas ocorrem, os ideofones do Changana, como vimos nos exemplos, dependem muito do 
contexto para que se acesse o seu significado, por isso que para a interpretação do seu significado, os locutores devem ter um conhecimento para além do transmitido linguisticamente e para além do que seria transmitido centralmente pelo verbo. Concordamos, pelas razões acima expostas, que se atribua aos ideofones a característica de serem palavras ou expressões sinestésicas que apresentam uma tendência de ter uma função emotiva/expressiva e de estarem associados à fala e a registros dramáticos da fala, assim como uma representação viva de uma ideia, num som (Kimeny, s.d), mas verificamos que eles também desempenham a função predicadora, embora estejamos cientes de que nesta língua os verbos é que são predicadores não marcados e ideofones predicadores marcados.

\section{Considerações Finais}

Como conclusões, podemos afirmar que o Princípio de Marcação se revela bastante útil para a compreensão dos ideofones do Changana. Nosso objetivo principal foi o de mostrar como o Princípio de Marcação pode contribuir para a descrição dos ideofones e diferenciá-los dos verbos, seus "concorrentes", na predicação de ações na língua Changana. Para tal, partimos de três princípios, o Princípio meta-icônico da marcação, a Frequência e Dependência do contexto. Feita a análise, concluímos que os ideofones marcam cenas intensas que ocorrem em situações específicas distintas do estado normal das coisas na língua. Eles atuam como predicadores marcados, focalizando mais os elementos periféricos, apesar de também exigir os elementos nucleares para a interpretação do seu significado, o que nos leva a concluir que ideofones são, em relação aos verbos, predicadores marcados e os verbos predicadores prototípicos, com efeito, os verbos ocorrem como predicadores básicos e os ideofones para ações e/ou eventos marcadas, aplicando-se deste modo o Princípio meta-icônico da marcação, uma vez que ideofones apresentam uma complexidade estrutural (Givon, 1995), pois ocorrem sempre com um verbo defectivo que os situa em termos de tempo e de aspecto, tornando os ideofones complexos estruturalmente.

Apresentam também complexidade cognitiva, pois são também funcionalmente mais complexos. Em termos de Frequência, concluímos que sendo os ideofones predicadores/palavras marcados, eles apresentam baixa frequência na língua, pois geralmente são chamados a predicar ações específicas. No que respeita à Dependência do contexto, como defende Givón (2001), a marcação não diz respeito apenas a categorias linguísticas, mas também a categorias comunicativas em que elas ocorrem. No caso dos ideofones, concluímos que para ativar os elementos periféricos e acessar o significado dos ideofones, há que recorrer para além das categorias linguísticas, a categorias comunicativas em que eles são 
usados, tais como, contexto, finalidade, intenção dos locutores, etc. Sendo assim, podemos afirmar seguramente que os ideofones do Changana são palavras marcadas e que os três princípios givonianos se aplicam neles.

\section{Referências}

Araújo, Gabriel. Ideofones na língua sãotomense. Papia, n. 19, p. 23-37, 2009.

Beck, David. Ideophones, adverbs and predicate modifiers in Upper Necaxa Totonac. Departament of Linguistics, University of Alberta, 2005.

Biriate, Mário. Avanços no estudo de Ideofones. (Blog desenvolvido por Mário Biriate), 2014. Disponível em: <http://uptete.blogspot.com.br/>. Acesso em: 21 ago. 2015.

Bybee, Joan. Markedness: iconicity, economy, and frequency. 131-146, 2010. Disponível em: <Filepath:d:/womat-filecopy/0001154332.3D>. Acesso em: 16 set. 2015.

Cardoso, Tiago. Processos de concordância verbal com SN-Sujeitos complexos à luz do princípio da marcação de Talmy Givón. Rio Grande: NEELP/FURG, 2014.

Doke, Clement. Bantu Linguistic Terminology. London: Longman, 1935.

Epps, Patience; Salanova, Andrés. A linguística amazônica hoje. Liames, n. 12, p. 07-37, 2012.

ETHNOLOGUE. Languages of the world. Disponível em: <https://www.ethnologue.com/ country/MZ> . Acesso em: 14 mar. 2017.

Ferreira, Marília. Como são apresentados sons e imagens em Parkatêjê. Signótica, Goiânia, vol. 23, n. 2, p. 403-414, jul./dez. 2011.

Gabas Jr., Nilson; Auwera, Johan. Ideofones in Karo. In: Achard, Michel; Kemmer, Suzanne (Org.). Language, culture and mind. Belgium: University of Antwerp, 2004. p. 397 - 411.

Givón, Talmy. Functionalism and grammar. Philadelphia: John Benjamin's Publishing Company, 1995.

Givón, Talmy. Syntax: an introduction. Amsterdam: John Benjamin's Publishing Company, 2001.

INE. Moçambique-projecções 2007 2040. Maputo: INE, 2016. Disponível em: <http://www. ine.gov.mz/estatisticas/estatisticas-demograficas-e-indicadores-sociais/projeccoes-da-populacao/ mocambique_projeccoes_2007_2040.xls/view >. Acesso em: 23 fev. 2017.

Kimeny, Alexandre. Inconicity of ideophones. In: Kinyarwanda: form, function, content and context. Califórnia State University at Sacramento, Califórnia, [s.d]. Disponível em: http://www. kimenyi.com/iconicity-of-ideophones-inkinyarwanda.php. Acesso em: mai. 2015.

Kulemeka, Andrew. Sound Symbolic and Grammatical Frameworks: a typology of ideofones, Asian and African languages. South African Journal of African Languages, South Africa, vol. 15, n. 2, p. 73-84 1995.

Langa, David. Ideofones em Changana. In: Ngunga, Armindo; Pereira, Inocêncio. (Org.). Progressos da Investigação em Ciências Sociais e Humanas. Maputo: Imprensa Universitária, 2004. p. 59-77. 
Miti, Lazarus. Comparative bantu phonology and morphology. Cape Town: CASAS, 2006.

MOÇAMBIQUE. Constituição da República de Moçambique. Maputo: Imprensa Nacional, 2004, artigos 09/10, dispõem sobre línguas nacionais e língua oficial. Disponível em: <http://www. mozambique.mz/pdf/constituicao> . Acesso em: 12 mai. 2017.

Ngunga, Armindo. Introdução à linguística bantu. Maputo: Imprensa Universitária, 2004.

Ngunga, Armindo.; Faquir, Osvaldo. Padronização da ortografia de línguas moçambicanas: relatório do III seminário. Maputo: Centro dos Estudos Africanos, 2011.

Nhampoca, Ezra. Revisitando alguns ideofones do Changana. In: Ngunga, Armindo (Org.). Lexicografia e descrição das línguas bantu. Maputo: Centro de Estudos Africanos, 2009. p.137-146.

Nhampoca, Ezra. Uma proposta metodológica para a compilação de um dicionário de ideofones do Changana. 2010. 67f. Dissertações (Mestrado em Linguística) - Faculdade de Letras e Ciências Sociais da Universidade Eduardo Mondlane, Maputo, 2010.

Nhampoca, Ezra. Um estudo preliminar sobre alguns aspectos da morfologia dos ideofones do Changana. Linguasagem, São Carlos, vol. 24 n.1, 16 p. 2015.

Nhampoca, Ezra. Compilação de um dicionário de ideofones do Changana: uma proposta metodológica. Saarbrücken: Novas Edições Acadêmicas, 2016.

Patel, Samima. Olhares sobre a educação bilingue e seus professor numa região de moçambique. 2006. 129 f. Dissertação (Mestrado em Linguística Aplicada) - Programa de Pós - Graduação em Linguística Aplicada do Instituto de Estudos da Linguagem - Universidade Estadual de Campinas, 2006.

Ribeiro, Armando. Dicionário gramatical changana. Maputo: Paulinas, 2010.

Silva, Cláudia Alexandra. Marcação: algumas considerações sobre o conceito a nível da fonologia. eLinUP, vol. 3, n. 1, 2011.

Sitoe, Bento. Dicionário changana - português. Maputo: INDE, 1996.

Sitoe, Bento. Dicionário changana - português. 2a ed. Maputo: Textos Editores, 2012.

Sitoe, Bento. Línguas moçambicanas, como estamos? In: Serra, Carlos. (Org.). Estão as línguas nacionais em perigo? Cadernos de Ciências Sociais. Maputo: Escolar Editora, 2014, p. 37-75.

Sitoe, Bento; Ngunga, Armindo. Padronização da ortografia de línguas moçambicanas: Relatório do II Seminário. Maputo: NELIMO, 2000.

Timbane, Alexandre. Análise sóciodiscursiva da "saudação" do grupo étnico-linguístico Tsonga de Moçambique. Educação, cultura e sociedade, São Paulo, v. 4, n. 2, p. 90-105, jul./dez. 2014.

UNIVERSIDADE EDUARDO MONDLANE. Secção de Línguas Bantu. Linguas Bantu: as nossas línguas. Maputo, 2014. 1 folder.

UNIVERSIDADE FEDERAL DE MINAS GERAIS. Laboratorio de Línguas Africanas, 2015. Disponível em: <http://www.letras.ufmg.br/laliafro/projeto.html> . Acesso em: 23 fev. 2016. 